\title{
Retrospective Clinical Evaluation of A Polyacid- Modified Resin Composite And Two Glass Ionomer Cements in Class II Cavities of Primary Teeth: Eighteen-Month Results
}

\author{
Resmiye Ebru Tirali ${ }^{1}$, Sevi Burçak Çehreli ${ }^{1}$ and Ersin Öğüş ${ }^{3}$ \\ 1,2Department of Pediatric Dentistry, Baskent University, Turky \\ ${ }^{3}$ Department of Biostatistics, Baskent University Faculty of Dentistry, Turky
}

Submission: December 29, 2016; Published: February 08, 2017

*Corresponding author: Resmiye EbruTirali, DDS,PhD, Baskent University Faculty of Dentistry,Department of Pediatric Dentistry, 11. sok No:26 Bahcelievler, 06490 Ankara Turkey, Fax:00903122152962; Email: ebru_aktepe@hotmail.com

\begin{abstract}
Objectives: The aim of this study was to evaluate and compare for 18 months, clinical characteristics of compomer and two glass ionomer restorative material in class II cavities of primary teeth.

Methods: Class II restorations performed in a pediatric dentistry clinic between Januray 2013 and March 2013 were evaluated. The materials were: a polyacid modified resin composite (compomer) (Dyract XP) with one-bottle bonding system (Prime \& Bond NT) and two different types of reinforced glass ionomer restorative material (ChemFil Rock and GC Equia) At the end of 18 months, the data of 37 children aged 5 to 8 could be evaluated. Clinical examination was performed by one experienced examiner using the modified Ryge criteria at baseline and six- and eighteen-months. Fisher-Freeman-Halton Exact Test was used to evaluate the obtained data.
\end{abstract}

Results: Compomer was the best scored material among all. Teeth restored with Chem Fil had a score of Charlie in $15 \%$ and $\% 35$ of all evaluated clinical situations on 6th and 18th months respectively. At the end of eighteen month Chem Fil group had a Charlie score of $35 \%$. Dyract XP and Equia groups didn't show any Charlie score at the end of 6 month. At the end of eighteen month Equia group dramatically showed Charlie score in $37,5 \%$ of the restorations for all evaluated clinical parameters excluding the marginal adaptation (33,3\%).

Conclusion: Reinforced glassionomer restorative materials used in Class II cavities for primary teeth were not suitable for long term.

Keywords: Glass ionomer cements; Polyacid-modified resin composite; Primary teeth

\section{Introduction}

The research for an ideal restoration has led to the development of several restorative techniques and materials in the primary dentition. Growing demand on esthetics and the controversy over amalgam have made resin-based composites or glass-ionomers more popular. Compomers (Poly-acid-modified resin composites) were introduced in 1993 as hybrid dental materials which combine the esthetics of traditional composite resins and the fluoride release properties of glassionomer cements [1]. Compomers are easy to handle, esthetic, have wear characteristics appropriate to primary teeth and they provide protection against caries $[2,3]$. Glass ionomers or glass polyalkenoate cements have been introduced to the dental armamentarium in 1970s. To date, they have been among the favorite materials in pediatric dentistry due to several properties such as biocompatibility; chemical adhesion to tooth,similar thermal expansion to that of tooth structure; uptake and release of fluoride as well as decreased moisture sensitivity. On the other hand, the low mechanical strengths of the existing conventional glass ionomer formulations make the material unsuitable for use in high-stress sites, such as Class II restorations [4-6]. For this reasons efforts for improvement have been made in several aspects. The manufacturer of a recently launched GIC (ChemFil Rock, Dentsply) followed a different approach to enhance material's stability, claiming that surface protection in the form of resin coating is irrelevant for product's performance. An enhanced setting reaction in the new GIC is supposed, due to the zinc content as part of its glass particles, thus leading to a higher with similar working time and application as regular GICs [7]. Similarly, EQUIA (GC, Tokyo, Japan) is a newly developed fast setting high-viscosity glass-ionomer cement with a nanofilled resin coat as a protective coating (G-Coat Plus, GC). The manufacturers of EQUIA claim that the material has increased fracture toughness, flexural strength, 
and flexural fatigue resistance which are required in stress bearing restorations [8]. The aim of this observational retrospective study was to test the clinical success of the two newly launched glass ionomer restorative material in comparison with compomer in class II cavities of primary teeth. The null-hypotheses tested there will be no difference in the clinical performance among compomer, Chemfil Rock and GC Equia.

\section{Materials and Methods}

This clinical study was approved by Baskent University Institutional Review Board and Ethics Committee (Project no: D-KA16/02)It was supported by Baskent University Research Fund and performed at the Department of Pediatric Dentistry, Baskent University. An a priori power analysis was performed by using statistical program $G^{*}$ Power to determine required sample size for chi-squared analysis. The sample size calculated as 60 primary teeth in total which produced $\% 80$ power with $\% 45$ effect size at $\% 5$ significance level. 75 patients were randomly selected from a data pool in Baskent University Pediatric Dentistry Department among the ones who received Class II restorations with either a compomer or a reinforced glass ionomer material. All subjects enrolled in this research have given their informed consent which has been approved by my institutional committee on human research and this protocol has been found acceptable by them. All records are kept in a software called Nucleus, including the Ryge criteria of restorations. Each patient received three restorations due to caries of the primary molar teeth, resulting in 180 total restorations. However, after 18 months only 37 patients $(25$ male and 12 female, with a mean age: 6,45 ) with 66 teeth were available for examination. Teeth available for examination at the end of the eighteen month consisted of 20 maxillary first molar, 17 maxillary second molar, 21 mandibular first molar, 8 mandibular second molar. All cavities were prepared and the restorations placed by the same operator. The manufacturer's instructions were strictly followed while placing restorative materials. Isolation was achieved with cotton rolls and suction in all cases.Below are the steps followed during placement of three restorative materials. Table 1 lists the materials used in this study. Dyract XP (Dentsply, Konstanz, Germany): One coat of Prime \& Bond NT (Dentsply, United States) was applied. The cavity surface was saturated with the adhesive and left undisturbed for 20 seconds. The excess solvent was removed with a gentle blow of air. The operator checked the surfaces to confirm that they were uniformly glossy before light curing for 10 seconds (Hilux Optimax, Benlioğlu Dental, Turkey). DyractXP was placed and light-cured for 40 seconds.
Following removal of the excess material with fine diamond burs and strips, the restorations were finished and polished with SofLex abrasive disks (3M ESPE). ChemFil Rock (Dentsply, Konstanz, Germany): The tooth surface rinsed with water spray and carefully removed excess rinsing water with air spray. Cavity surface kept moist.The capsule activated by pressing the capsule onto a stable surface and depressing the plunger to its limit. Immediately place the activated capsule in a capsule mixer (4000-4500 oscillations/ minute) and mix for 15 seconds. The capsule removed from the capsule mixer and place into the Capsule Extruder and applied to the cavity. Removal was excessed and contoured immediately after placement. Finishing started no earlier than 4 minutes 30 seconds after end of working time (i.e. 6 minutes after activation) with cups and discs. EQUIA Fil (GC, Tokyo, Japan): Gc Cavity Conditioner was applied (10 seconds) to the bonding surfaces using a cotton pellet. It was rinsed thoroughly with water and excess waterwas dried by gently blowing with an air syringe. Before activation the capsule, it was shaked. It was pushed until plunger flushed with the main body. The capsule immediately set into a mixer and mix for 10 seconds (+/- 4,000RPM) and loaded into the Gc Capsule Applier (The working time is 1 minute 15 seconds from start of mixing at $\left.23^{\circ} \mathrm{C}\left(73.4^{\circ} \mathrm{F}\right)\right)$. After applying to the cavity removal was excessed and contoured immediately after placement. EQUIA Coat applied and light cured with a visible light curing unit $\left(>500 \mathrm{~mW} / \mathrm{cm}^{2}\right.$ : Halogen for 20 seconds). The setting reaction takes 2 minutes 30 seconds from start of mixing. After that, the restoration was finished with rubber cups and discs. The restorations were evaluated by one experienced calibrated examiners using the modified Ryge criteria [9]. At baseline, six- and eighteen-month recalls; marginal discoloration, marginal adaptation, secondary caries, anatomic form, surface texture, retention, postoperative sensitivity,loss of enamel were evaluated. The data are recorded for every restoration in a programme called Nucleus. According to the modified Ryge criteria, Alpha (A) indicates a clinically ideal situation, Bravo B) indicates a clinically acceptable situation, except for caries, which requires replacement of the restoration; Charlie (C) is a clinically unacceptable situation, where placement of the restoration is required. In the study Fisher-Freeman-Halton Exact Test were used to test independence between the restorative materials used for the restoration of primary teeth after Class II cavity preparation and the categorical variables assessed using modified Ryge criteria.The level of significance for all statistical tests was set at $\alpha=5 \%$.When the test result is significant at $\% 5$ significance level, Cramer's V correlation coefficient is calculated to determine the strength and the direction of the relationship.

Table 1: Product name, manufacturer, composition of the materials tested

\begin{tabular}{|c|c|c|}
\hline Materials & Manufacturer & Composition \\
\hline Dyract XP & Dentsply, Konstanz, Germany & $\begin{array}{c}\text { Urethane dimethacrylate (UDMA), Carboxylic } \\
\text { acid modified dimethacrylate (TCB resin), } \\
\text { Camphorquinone, Ethyl-4(dimethylamino) } \\
\text { benzoate, Butylated hydroxy toluene (BHT), UV } \\
\text { stabilizer, Strontium-alumino-sodium-fluoro- } \\
\text { phosphor-silicate glass, Highly dispersed silicon } \\
\text { dioxide, Strontium fluoride, Iron oxide pigments } \\
\text { and titanium oxide pigments }\end{array}$ \\
\hline
\end{tabular}




\section{Advances in Dentistry \& Oral Health}

\begin{tabular}{|c|c|c|}
\hline ChemFil Rock & Dentsply, Konstanz, Germany & $\begin{array}{c}\text { Calcium-aluminium-zinc-fluoro-phosphor- } \\
\text { silicate glass, polycarboxylic acid, iron oxide } \\
\text { pigments, titanium dioxide pigments, tartaric } \\
\text { acid, water }\end{array}$ \\
\hline EQUIA Fil & GC, Tokyo, Japan & $\begin{array}{c}\text { Polyacrylic acid, aluminosilicate glass, distilled } \\
\text { Water }\end{array}$ \\
\hline
\end{tabular}

\section{Results}

After 6 months, only teeth restored with ChemFil were scored Charlie (C) for all evaluated clinical situations (Table 2-5). The failure rate was $15 \%$. Statistical analysis showed there is a significant difference among the evaluated clinical situation except marginal adaptation (Table 2). Also at the end of eighteen month ChemFil group had a rating of $35 \%$ exactly same significance levels. Dyract XP and Equia groups didn't show any Charlie score at the end of 6 month. At 18 month Equia group rated Bravo in Table 2: Behaviour regarding Marginal Discoloration and Marginal Adaptation for tested materials.

\begin{tabular}{|c|c|c|c|c|c|c|c|c|c|c|c|c|}
\hline \multirow{3}{*}{$\begin{array}{c}\text { Criteria } \\
\text { (\%) }\end{array}$} & \multicolumn{6}{|c|}{ Marginal Discoloration } & \multicolumn{6}{|c|}{ Marginal Adaptation } \\
\hline & \multicolumn{3}{|c|}{6 Months } & \multicolumn{3}{|c|}{18 Months } & \multicolumn{3}{|c|}{6 Months } & \multicolumn{3}{|c|}{18 Months } \\
\hline & Com & Chem Fil & Equia & Com & Chem Fil & Equia & Com & $\begin{array}{c}\text { Chem } \\
\text { Fil }\end{array}$ & Equia & Com & $\begin{array}{c}\text { Chem } \\
\text { Fil }\end{array}$ & Equia \\
\hline Alfa (A) & 86,4 & 75,0 & 100,0 & 77,3 & 50,0 & 54,0 & 86,4 & 70,0 & 91,7 & 81,8 & 50,0 & 58,3 \\
\hline $\begin{array}{l}\text { Bravo } \\
\text { (B) }\end{array}$ & 13,6 & 10,0 & 0,0 & 18,2 & 15,0 & 8,3 & 13,6 & 15,0 & 8,3 & 13,6 & 15,0 & 8,3 \\
\hline $\begin{array}{l}\text { Charlie } \\
\text { (C) }\end{array}$ & 0,0 & 15,0 & 0,0 & 4,5 & 35,0 & 37,5 & 0,0 & 15,0 & 0,0 & 4,5 & 35,0 & 33,3 \\
\hline $\mathrm{p}$ value & \multicolumn{3}{|c|}{$0.016^{*}$} & \multicolumn{3}{|c|}{0,05} & \multicolumn{3}{|c|}{0.156} & \multicolumn{3}{|c|}{0,065} \\
\hline
\end{tabular}

* Significant (Fisher Exact test).

Table 3: Behaviour regarding Secondary Caries and Anatomic form for tested materials.

\begin{tabular}{|c|c|c|c|c|c|c|c|c|c|c|c|c|}
\hline \multirow{3}{*}{$\begin{array}{c}\text { Criteria } \\
(\%)\end{array}$} & \multicolumn{6}{|c|}{ Secondary Caries } & \multicolumn{6}{|c|}{ Anatomic Form } \\
\hline & \multicolumn{3}{|c|}{6 Months } & \multicolumn{3}{|c|}{18 Months } & \multicolumn{3}{|c|}{6 Months } & \multicolumn{3}{|c|}{18 Months } \\
\hline & Com & Chem Fil & Equia & Com & Chem Fil & Equia & Com & Chem Fil & Equia & Com & $\begin{array}{l}\text { Chem } \\
\text { Fil }\end{array}$ & Equia \\
\hline $\operatorname{Alfa}(\mathrm{A})$ & 95,5 & 751,0 & 100,0 & 90,9 & 50,0 & 54,2 & 95,5 & 75,0 & 100,0 & 90,9 & 50,0 & 54,2 \\
\hline $\begin{array}{c}\text { Bravo } \\
\text { (B) }\end{array}$ & 4,5 & 10,0 & 0,0 & 4,5 & 15,0 & 8,3 & 4,5 & 10,0 & 0,0 & 4,5 & 15,0 & 8,3 \\
\hline $\begin{array}{l}\text { Charlie } \\
\text { (C) }\end{array}$ & 0,0 & 15,0 & 0,0 & 4,5 & 35,0 & 37,5 & 0,0 & 15,0 & 0,0 & 4,5 & 35,0 & 37,5 \\
\hline $\mathrm{p}$ value & \multicolumn{3}{|c|}{$0,014^{*}$} & \multicolumn{3}{|c|}{$0,015^{*}$} & \multicolumn{3}{|c|}{$0,014^{*}$} & \multicolumn{3}{|c|}{$0,015^{*}$} \\
\hline
\end{tabular}

*Significant (Fisher Exact test)

Table 4: Behaviour regarding Surface texture and Retention for tested materials.

\begin{tabular}{|c|c|c|c|c|c|c|c|c|c|c|c|c|}
\hline \multirow{3}{*}{$\begin{array}{c}\text { Criteria } \\
\text { (\%) }\end{array}$} & \multicolumn{6}{|c|}{ Surface texture } & \multicolumn{6}{|c|}{ Retention } \\
\hline & \multicolumn{3}{|c|}{6 Months } & \multicolumn{3}{|c|}{18 Months } & \multicolumn{3}{|c|}{6 Months } & \multicolumn{3}{|c|}{18 Months } \\
\hline & Com & Chem Fil & Equia & Com & Chem Fil & Equia & Com & $\begin{array}{c}\text { Chem } \\
\text { Fil }\end{array}$ & Equia & Com & $\begin{array}{c}\text { Chem } \\
\text { Fil }\end{array}$ & Equia \\
\hline Alfa (A) & 95,5 & 75,0 & 100,0 & 90,5 & 50,0 & 54,2 & 95,5 & 75,0 & 100,0 & 95,5 & 50,0 & 54,2 \\
\hline Bravo (B) & 4,5 & 10,0 & 0,0 & 4,0 & 15,0 & 8,3 & 4,5 & 10,0 & 0,0 & 0,0 & 15,0 & 8,3 \\
\hline Charlie (C) & 0,0 & 15,0 & 0,0 & 4,5 & 35,0 & 37,5 & 0,0 & 15,0 & 0,0 & 4,5 & 35,0 & 37,5 \\
\hline $\mathrm{p}$ value & \multicolumn{3}{|c|}{$0,014^{*}$} & \multicolumn{3}{|c|}{$0,015^{*}$} & \multicolumn{3}{|c|}{$0,014^{*}$} & \multicolumn{3}{|c|}{$0,004 *$} \\
\hline
\end{tabular}

* Significant (Fisher Exact test). 


\section{Discussion}

In pediatric dentistry, Class II restorations are the most technically challenging ones regarding the visual inspection, moisture control, placement and light curing of the restorative material [10]. This study examined the clinical performance of three restorative materials (Dyract XP/Prime \& Bond NT, ChemFil Rock and GC Equia) in Class II cavities. After eighteen months, compomer restorations performed a high clinical success rate (95.5\%). The other tested materials showed lower performance than compomer at the end of 18 month. The clinical performance of Equia was very similar with that of compomer for the first 6 months. However, according to the Ryge criteria, the performance of the material was lower than that of compomer at the end of 18 months. Yet, it should be noted that the material's marginal adaptation was still comparable with compomer. These results are in accordance with the review that examines the issue"Restorative materials in the primary dentition" which showed that compomers exhibit a clear potential as the restorative material upon analyzing the clinical performance [11]. Ylldız etal. [12] evaluated the fracture strength of various restorative materials for primary molars in dovetail and box-only class II cavity designs. The fracture strength of the compomer and composite groups were significantly higher than that of the GIC and RMGIC groups. Qvist et al. [13] reported that the GIC restorations' main reason for the failure of in class II cavities is fracture of restoration which was also the case herein. This mode of fracture indicates inadequate physical properties of GIC. First, one cannot account for all variables that may influence survival of restorative materials such as operator's skills as well as variables related to the patients including behavior, caries rate, fluoride exposure, oral hygiene, etc. There have been very few studies with large data sets documenting the clinical success of Vitremer or any other RMGIC. Published one such study with similar conditions to the present study. Their retrospective study used Vitremer in the private practice of a pediatric dentist. The study included 406 Class II restrations and 393 Class I restorations. The authors found an overall success rate of $93 \%$ for all Vitremer restorations placed in this over a three-year period [14]. The handling characteristics of dental restorative materials are also very important in reducing the chances of early failure [15]. Compomers' most important feature is their easy handling, particularly in dentistry for children increases clinical acceptance [2]. But the problems like poor cooperation during dental procedures causes difficulty in preventing saliva contamination. Therefore the use of glass ionomers is inevitable due to the major advantages include chemical adhesion to dentin and enamel, fluoride release, high tissue tolerance, and pulpal biocompatibility. In the present study, Equia group showed significantly high scores compared with the other tested materials after 6 months, but at the end of eighteen month clinical performance significantly reduced. Molina et al. [16] tested diametric tensile, compressive and flexural strengths exists between: EQUIA system and Chemfil Rock and with those of glassionomers currently in use. The EQUIA and Chemfil Rock had significantly higher mean scores for all the three strength variables than. And they concluded that the EQUIA system had significant higher mean scores for diametral tensile and flexural strengths than the Chemfil Rock. This explained previously statements of Crisp and Wilson [17] presumed that the high affinity of water to GICs is caused by the ion-depleted siliceous phase, whose behavior is analogical to silica gel, taking up water from the surroundings. Xie et al. [18] conclude that a less dense surface, or rather larger and higher amounts of voids result in worse mechanical properties. Similar is valid also for GIC containing high amounts of zinc embodied in the glass powder, since an enhanced network connectivity will occur, thus raising the ability of the material to form a cement with acrylic acid. The setting time was also shown to decrease, making the resulting GIC more resistant against hydrolysis and, finally, inducing in the material a higher strength [19]. Another practical difficulty experienced by the operators was the displacement of small parts of the restorative material at the time of removing the matrix band. Inpractice this observation means that a glass ionomer restorations runs a high risk of being damaged by the patient even before it has been setted completely. The first null hypotheses was; that no difference in clinical performance exists between the reinforced glass ionomer systems and the a commonly used compomer were rejected. The second null-hypothesis was partly rejected.

\section{Conclusion}

In the present study, when compared with two reinforced GICs, compomer showed higher clinical performance in class II cavities of primary teeth at the end of 18 months. In class II cavities of primary teeth, reinforced glass ionomers may be preferable in children with lack of cooperation as well as good oral hygiene as interim therapeutic restorations. Yet, considering the drawbacks of the present study, further research are required to confirm the results obtained herein.

\section{References}

1. Krejci I, Gebauer L, Häusler T, Lutz F (1994) Composite polymers--an amalgam substitute for deciduous tooth cavities? Schweiz Monatsschr Zahnmed 104(6): 724-730.

2. Berg JH (1998) The continuum of restorative materials in pediatric dentistry-a review for the clinician. J Pediat Dent 20(2): 93-100.

3. Pascon FM, Kantovitz KR, Caldo Teixeira AS, Borges AF, Silva TN, et al. (2006) Clinical evaluation of composite and compomer restorations in primary teeth: 24-month results. J Dent 34(6): 381-388.

4. Wilson AD (1990) Resin-modified glass-ionomer cements. Int J Prosthodont 3(5): 425-429.

5. McLean JW (1992) The clinical use of glass-ionomer cements. Dent Clin North Am 36(3): 693-711.

6. Christensen GJ (1994) Why is glass ionomer cement so popular? J Am Dent Assoc 125(9): 1257-1258.

7. Dentsply (2011) Wissen schaftliches Kompendium ChemFil Rock.

8. Zoergiebel J, Ilie N (2013) Evaluation of a conventional glass ionomer 
cement with new zinc formulation: Effect of coating, aging and storage agents. Clin Oral Investig 17(2): 619-626.

9. Ryge G (1980) Clinical criteria. Int Dent Journal 30(4): 347-358.

10. Laegreid T, Gjerdet NR, Vult von Steyern P, Johansson AK (2011) Class II composite restorations: importance of cervical enamel in vitro. Oper Dent 36(2): 187-195.

11. Krämer N, Lohbauer U, Frankenberger R (2007) Restorative materials in the primary dentition of poli-caries patients. Eur Arch Paediatr Dent 8(1): 29-35.

12. Yildiz E, Simsek M, Pamir Z (20016) Fracture strength of restorations in proximal cavities of primary molars. Scanning 38(1): 43-49.

13. Al Angari SS, Hara AT, Chu TM (2014) Physicomechanical properties of a zinc-reinforced glass ionomer restorative material. J Oral Sci 56(1): 11-16.

14. Croll, TP, Bar-Zion, Y, Segura, A, Donly KJ (2001)Clinical performance of resin-modied glass ionomer cement restorations in primary teeth, a retrospective evaluation. JADA 132(8): 1110-1116.

15. Roeters JJM, Frankenmolen F, Burgersdijk RCW, Peters TC (1998) Clinical evaluation of Dyract in primary molars: 3- year results Am J Dent 11(3): 143-148.

16. Molina GF, Cabral RJ, Mazzola I, Lascano LB, Frencken JE (2013) Mechanical performance of encapsulated restorative glass-ionomer cements for use with Atraumatic Restorative Treatment (ART). J Appl Oral Sci 21(3): 243-249.

17. Crisp S, Wilson AD (1974) Reactions in glass ionomer cements: I. Decomposition of the powder. J Dent Res 53(6): 1408-1413.

18. Xie D, Brantley WA, Culbertson BM, Wang G (2000) Mechanical properties and microstructures of glass-ionomer cements. Dent Mater 16(2): 129-138.

19. Darling M, Hill R (1994) Novel polyalkenoate (glass-ionomer) dental cements based on zinc silicate glasses. Biomaterials 15(4): 299-306

\begin{tabular}{l} 
Your next submission with Juniper Publishers \\
will reach you the below assets \\
- Quality Editorial service \\
- Swift Peer Review \\
- Reprints availability \\
- E-prints Service \\
- Manuscript Podcast for convenient understanding \\
- Global attainment for your research \\
- Manuscript accessibility in different formats \\
( Pdf, E-pub, Full Text, Audio) \\
- Unceasing customer service \\
Track the below URL for one-step submission \\
https://juniperpublishers.com/online-submission.php \\
\hline
\end{tabular}

